\title{
A COMPOSITE MANUFACTURING GROWTH INDEX: 1954-1978
}

\author{
Edward Nissan and Regina Caveny*
}

\section{Introduction}

In recent years, there has been a growing interest by economists in manufacturing productivity trends in the United States. Accordingly, several studies relating to the regional aspect of growth and decline of productivity were undertaken. Notable among these is Hulton and Schwab (1984). Their work provides an assessment of the sources of economic growth as the basis of regional variation in productivity for two periods, 1965-73 and 1973-78. The primary interest was a comparison of the two periods.

Moomaw and Williams (1984) have expanded the work of Hulton and Schwab (1984) by presenting an interstate comparison of economic growth in manufacturing. To obtain the data on growth of output, input and the rate of technological change, Moomaw and Williams adopted a method founded on the economic theory of production. A translog production function with constant returns to scale was chosen for the analysis. Their study resulted in a set of data which separates growth of capital and labor inputs from growth in the rate of technological change for each of the 48 continental states. Thus their work focuses on the individual states rather than principally on regions.

The purpose of this paper is to construct a composite index based on the data generated by Moomaw and Williams (1984). Composite index values are of general interest because they allow comparison based on more than one criterion variable simultaneously. The proposed index has the additional advantage of being an absolute, rather than relative measure. This property allows standard statistical analyses, as will be illustrated.

Using the data for the three growth factors capital, labor and technological change - the paper ranks the states, and consequently the regions. Hence, while the analyses in the previous works were conducted

\footnotetext{
*Professor of Economics, University of Southern Mississippi, and Instructor of Management Information Sciences, University of Southern Mississippi. The authors gratefully acknowledge the generosity of Roland L. Moomaw and Martin Williams for allowing the use of their data on which this work is based. Of course, the results contained in this paper are the sole responsibility of the authors.
}

with productivity as the center of interest, the analysis here provides a different look at interstate and regional variation by taking into account simultaneously three factors that contribute to manufacturing growth - labor, capital and technological change.

Restricted by the data availability as generated by Moomaw and Williams (1984), the paper covers the period from 1954 through 1976, divided into three subperiods, 1954-65, 1965-73 and 1973-76. The analysis will show that although individual states and regions have in general maintained their relative position in the rankings during consecutive time spans, nevertheless there were significant shifts among the states and regions as contrasted between the earlier and later periods.

In the second section, a discussion of the proposed index will be given. The third section will include the empirical results and the statistical analysis.

\section{A Measure of Ranking}

The proposed index will incorporate technological change, labor and capital as the three basic factors which contribute to growth rates in manufacturing. The index is described by Hellwig (1972), and is known as the "Wroklaw Taxonomy". In a sense, the Wroklaw Taxonomy is a distance measure which expresses differences and similarities as $\mathrm{n}$-dimensional points.

To have all the variables on a similar scale requires a rescaling of all the data values. The most widely used procedure is to transform the variable linearly by defining

$$
z_{i j}=\left(x_{i j}-\overline{x_{j}}\right) / s_{j},
$$

where

$$
\overline{x j}=\sum_{i=1}^{n} x_{i j} / n,
$$

and

$$
s_{j}=\left[1 / n \sum_{i=1}^{n}\left(x_{i j}-x_{j}\right)^{2}\right] 1 / 2
$$

Here, $x_{i j}$ represents the given value that state $i(i=1$, $\ldots, 48)$ takes for factor $\mathrm{j}(\mathrm{j}=1,2,3)$ and $\mathrm{z}_{\mathrm{ij}}$ is the 
transformed variable with mean and standard deviation equal to zero and one, respectively.

Then, the three dimensional distance $d\left(z_{i}, z_{0}\right)$ for state $i$, from the ideal $z_{0}$ is given by

$$
d\left(z_{i}, z_{0}\right)=\left[\sum_{j=1}^{3}\left(z_{i j}-z_{0 j}\right)^{2}\right] 1 / 2, i=1,2, \ldots, 48 .
$$

The ideal $\mathrm{z}_{0}$ is a composite of the most favorable figure for each factor. Specifically, the ideal posesses the largest capital, labor and technological growth rates for the time span under consideration. By definition, it may be observed that the smaller the distance measure for a particular state, the closer it is to the ideal $z_{0}$. Therefore, smaller index values are indicative of better performance.

\section{Empirical Results}

\section{Statistical Analysis of Interstate Rankings}

Moomaw and Williams (1984) considered the time span from 1955 to 1976 , and the three sub-periods 1955 $65,1965-73$ and 1973-76. Thus it was possible to compute four separate index values for each state. Values for the composite index are presented in Table 1. The rankings based on the index are in ascending order, with the smallest index value receiving a 1 . The table classifies the distribution of the states into eight regions as defined by the Bureau of Economic Analysis.

Inspection of the table shows that Florida achieved the closest distance to the composite ideal for the entire time period, 1955-1976, and the sub-period 1955-65. Arizona was closest to the ideal during the 1965-73 period while Nebraska headed the list during the most recent sub-period. The worst performances in terms of the three factors were recorded by New York for the 21year span, and Nevada, Tennessee and New Jersey for the three successive sub-periods, respectively.

To determine whether the states performed consistently over time, Spearman's correlation coefficients to compare the rankings were computed. The results are reported in Table 2.

All the coefficients except one (note the *) are significant at .01 . It can be concluded that relative position was generally maintained by the states in consecutive time spans. However, the non-significant coefficient of .056 correlating the rankings of the subperiods 1955-65 and 1973-76 indicates that a significant shift in performance among the states has occurred from the earliest to the latest periods.

\section{Statistical Analysis of Regional Rankings}

Since the index values are an absolute, rather than a relative measure, it was deemed appropriate to compare the performance of the regions with a one-way analysis of variance. A separate analysis was performed for each time span.

The analysis of variance procedure tests the null hypothesis that two or more population means are equal. Thus, in this case, the null hypothesis states that the eight regions do not differ significantly in their average index values. If the null hypothesis is rejected, then it may be concluded that at least one region has a significantly higher or lower average index value.

The null hypothesis was rejected for every time span. To identify the significant differences, Tukey's linear contrast procedure was used. This procedure ranks the means and then essentially compares all possible pairs. Ideally, Tukey's test identifies compact subgroups whose members are not distinguishably different from one another. However, the test may yield only individual significant differences without producing homogeneous subsets, as happened in this study. The rankings of the eight regions, from smallest to largest are presented in Table 3.

For the sub-period 1955-65, the procedure identified only one significant difference, between the Southeast and New England regions. Similarly, for the second sub-period, 1965-73, the Mideast was significantly different from the Southwest and the Plains while New England and the Great Lakes regions differed significantly from the Southwest only. Finally, during the most recent sub-period, the Mideast differed significantly from the Southwest, Rocky Mountain, Plains and Southeast regions.

In general, it can be observed from the rankings of the regions that the Southwest and Plains are consistently in the top half while the Mideast, New England and the Great Lakes are consistently in the bottom half. Also, the steady decline of the Southeast from the earliest to the latest time span may be observed.

$$
\text { References }
$$

Hellwig, Z. 1972. "On the Problem of Weighting in International Comparisons." In Toward a System of

Human Resources Indicators for Less Developed Countries. Z. Gostokowski (ed.), Wroclaw: The Polish Academy of Science Press.

Hulton, C. R. and P. M. Schwab. 1984. "Regional Productivity Growth in U.S. Manufacturing: 195178." American Economic Review. 74:152-162.

Moomaw, R. L. and M. Williams. 1984. "Regional Productivity Growth in U.S. Manufacturing." Paper presented at the Southern Economic Association Meetings, Atlanta, GA, November 14-16, 1984. 
TABLE 1

Computed Composite Index Values, By States and Regions

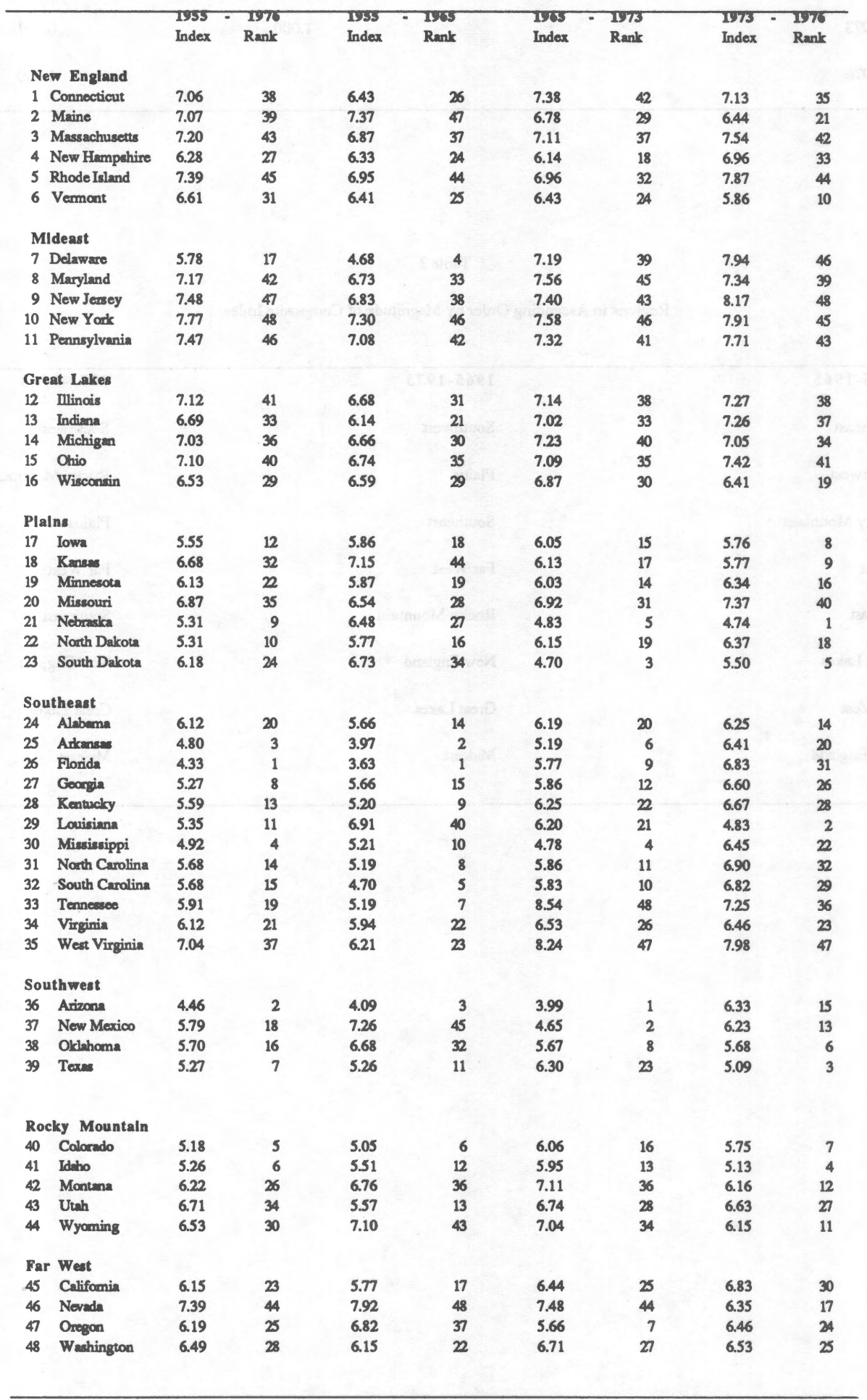


Table 2

Spearman's Rank Correlation Coefficients for the Index Measures

\begin{tabular}{lccc}
\hline & $1955-1965$ & $1965-1973$ & $1973-1976$ \\
$1955-1965$ & 1.000 & 0.369 & $0.056^{*}$ \\
$1965-1973$ & & 1.000 & 0.627 \\
$1973-1976$ & & & 1.000 \\
\hline
\end{tabular}

Table 3

Regions in Ascending Order by Magnitude of Composite Index

\begin{tabular}{lll}
\hline 1955-1965 & 1965-1973 & $1973-1976$ \\
Southeast & Southwest & Southwest \\
Southwest & Plains & Rocky Mountain \\
Rocky Mountain & Southeast & Plains \\
Plains & Far West & Far West \\
Mideast & Rocky Mountain & New England \\
Great Lakes & New England & Great Lakes \\
Far West & Great Lakes & Mideast \\
New England & Mideast & \\
\hline
\end{tabular}

